\title{
Interaction between Cyclist and Car during Broadside and Confrontation with Pedestrian Throw Formulas - Multibody Simulation
}

\author{
O. Fanta * \& K. Jelen \\ Department of Anatomy and Biomechanics, Faculty of Physical Education and Sport, Charles University \\ in Prague, Czech Republic \\ * Corresponding author: fantao@seznam.cz
}

H. Purš

Advanced Engineering, s.r.o., CAE Dep., Prague, Czech Republic

DOI: $10.2478 / \mathrm{v} 10158-010-0014-0$

\begin{abstract}
Although the issue of the injury of a cyclist in car collision is in lower when compared to that of pedestrians, we cannot ignore it completely. There is an increasing need to pay attention to bicycle safety due to the growing popularity of motorless single-track vehicles. This study investigates whether it is appropriate to analyze cyclist accidents using relations describing pedestrian throws and whether using simulation software Madymo models the side-impact collision caused by cars. This paper also describes how significant the form of the front parts of normal cars are, as well as the position of the cyclist on three types of bicycles. The analysis of formulas which estimate the car's speed before the impact contributes mainly to the field of judicial expertise and the investigation of car accidents.
\end{abstract}

KEY WORDS: Biomechanics, cycling, car accident, simulation software, throw distance.

\section{INTRODUCTION}

The interaction of the human body with a moving car is a significantly highlighted problem of biomechanics that has been intensely studied at many important institutions around the world (ADAC, TÜV, Mercedes-Benz, Škoda Auto, Czech Technical University in Prague - Faculty of Transportation, Charles University - Faculty of Physical Education and Sport, etc.). It is a complex problem of a mechanically complicated system of viscoelastic elements (segments of the body, tissues, organs, etc.) interconnected by joints with variable stiffness and controlled by the nervous system. Therefore, relevant results can be achieved only by studying the problem through intermediary steps, both with experimental and simulation methods using validated objects and a mutual comparison of its results.

A serious bicycle accident can affect anyone who rides a bike both on the street and in the countryside, either quickly or slowly. We can presume that there is no threat if we are riding a bicycle in a quiet neighborhood, but according to iBESIP (2008) most of the serious accidents in which cyclists were involved in happened close to home, and also the majority of fatal accidents have taken place in residential areas. 
The cyclist's head is affected in half of all cyclist accidents - it either hits the car or the ground. The most common site of injury for children, occurring after the fall of the bike, are: head $-44 \%$, arms $-27 \%$, stomach $-6 \%$ and knees $23 \%$ (iBESIP, 2008).

There were 77 cyclists killed on the Czech roads, including 2 children under the age of 14 years. Another 431 cyclists were seriously injured and 2516 slightly injured. These figures are but the tip of the iceberg, since it is only for those cases where an accident was reported to the Police and then appeared in the relevant statistics. The seriousness of accidents (deaths per 1000 accidents) caused by cyclists in 2008 was 19.6, the second highest after motorcycle riders. Out of the total number of 77 cyclists killed in an accident, 68 cyclists wore a helmet, i.e., $88.3 \%$. In the case of severe injuries 348 cyclists were not wearing a helmet $(80.7 \%)$ and in case of slight injuries 2041 cyclist were not wearing a helmet $(81.1 \%)$.

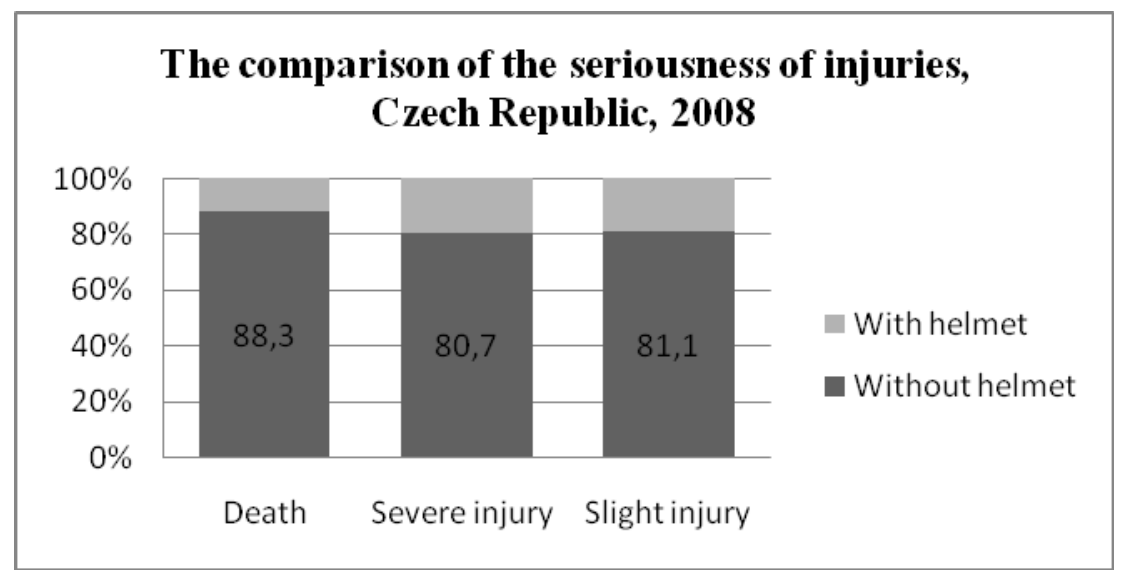

Figure 1 - The seriousness of injuries of cyclists with helmets and without helmet.

The side-impact (Figure 2) is the most common type of bicycle/car collision according to a study (Table 1) from the U.S. for the period 01/01/2007 to 06/30/2009 (Bike Accident Summary, 2010).

\begin{tabular}{|l|c|}
\hline Side-impact (Broadside) & 214 \\
\hline Overtaking Turn & 46 \\
\hline Leftward Turn (Approach Turn) & 33 \\
\hline $\begin{array}{l}\text { Contra-flow-lane ride } \\
\text { (Sideswipe) }\end{array}$ & 30 \\
\hline Impact with parked car & 8 \\
\hline Rear-impact & 8 \\
\hline Rearward ride & 5 \\
\hline
\end{tabular}

Table 1: Summary of types of collisions.

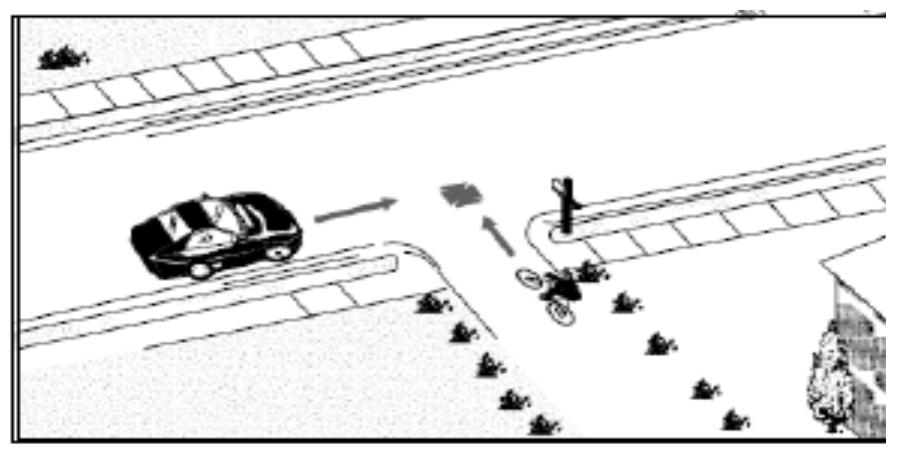

Figure 2: Side-impact (Bike Accident Summary, 2010).

\section{PEDESTRIAN THROW RELATIONS}

The usual question during the reconstruction of pedestrian accidents is how fast the car was driving when it hit the pedestrian. Groups of investigators determine the relations specially appointed to estimate the impact velocity of the vehicles. It is based on the throw distance measured directly on the spot. Such questions also arise with the accidents of cyclists. 
Can some of the patterns also be use when cyclists are concerned? Previously published formulas for calculating the throw distance of pedestrians will be considered to be relevant and will not be studied more deeply.

Schmidt, et al. (1971) assumed that the impact velocity is related to the distance between the contact point and the final point of rest of the pedestrians on the ground. By including the height of pedestrian's center of mass they set the relation:

$$
\operatorname{Vimp}=\sqrt{\mu^{2} \times h+2 \times \mu \times g \times D t-\mu \times h}
$$

Where:

Vimp $=$ impact velocity of the car $(\mathrm{km} / \mathrm{h})$

$\mu=$ coefficient of friction

$h=$ height of pedestrian's center of mass (m)

$D t=$ throw distance $(\mathrm{m})$

$g=$ acceleration due to gravity $\left(\mathrm{m} / \mathrm{s}^{2}\right)$

Collins, et al. (1979) also used the height of pedestrian's center of mass and adjusted their equations into the quadratic formula to get the impact velocity:

$$
\begin{gathered}
a=\frac{1}{254} \mu, \quad b=\frac{\sqrt{h}}{7,97}, c=-D t \\
\operatorname{Vimp}=\frac{\left[-b+\sqrt{b^{2}-4 a c}\right]}{2 a}
\end{gathered}
$$

Searle, et al. (1983) developed two equations that provide upper and lower estimates of speed and recognize the unique problem of collision, which is that the fall is accompanied by rolls and flight phases of the pedestrian.

$$
\begin{aligned}
& \operatorname{Vimp}_{\text {min. }}=\sqrt{\frac{2 \mu \cdot g \cdot D t}{1+\mu^{2}}} \cdot 1,097 \\
& V i m p_{\max .}=\sqrt{(2 \mu \cdot g \cdot D t)} \cdot 1,097
\end{aligned}
$$

Wood (1997) distinguishes whether the body was shifted across the hood (center of mass is above the leading edge of the car) or whether it was projected forward (center of mass is below the leading edge of the car), equations provide upper and lower estimates of impact velocity:

$$
\operatorname{Vimp}=K \times \sqrt{D t}
$$

Where:

$$
\begin{aligned}
& K_{\text {wrap MIN }}=3,3 ; \quad K_{\text {forward projection MAX }}=4,7 \\
& K_{\text {wrap MIN }}=3,01 ; \quad K_{\text {forward projection MAX }}=4,72
\end{aligned}
$$


Limpert (1999) estimates the accuracy of his equation within plus or minus $4 \mathrm{~km} / \mathrm{h}$. As opposed to the other relationships the coefficient of friction in Limpert equation is related to the tire and the road:

$$
\operatorname{Vimp}=6,6 \cdot \sqrt{8,4 \mu_{p}^{4}+\mu_{p} \cdot D t}-20 \mu_{p}^{2}
$$

Where:

$\mu_{p}=$ coefficient of friction - vehicle tire to roadway

Fugger et al. (2000) developed a simple non-linear equation to calculate the impact velocity. It is applicable for car to pedestrian impact on regular asphalt roadways.

$$
\operatorname{Vimp}=8,3604 \times D t^{0,6046}
$$

\section{MADYMO SIMULATION}

A model of a pedestrian was selected from a database of Madymo software for this simulation. It is a model of the human body $50 \%$ of standing pedestrians " $h$ ped50el". All the features of the model are adopted. The model of pedestrian was seated with the help of the JOINT parameters corresponding with modeled mountain bikes, road bikes and touring bikes (Figure 2). The deformation characteristic of the bike contact consists of the FORCE system with defined features. Contact between the wheel and the ground was taken from the Madymo database. The contact between a bike and vehicle components, and a bike and a model of a pedestrian, has also been defined. The FRIC.COEF has been used to set the friction between the bike and the pedestrian, especially saddle and handlebars. Gravity influences the whole system.
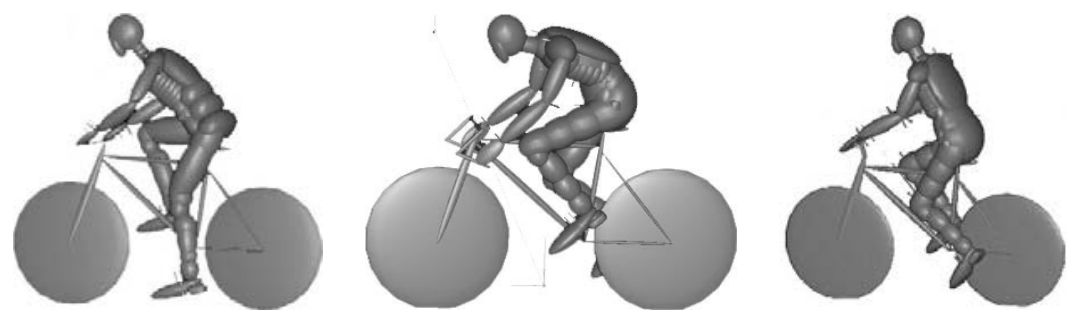

Figure 2 - Mountain, Road and Touring Bike.

A simplified vehicle model consists of planes, cylinders and ellipsoids where contact stiffness is defined. Reference values of stiffness (deformation characteristics) are used due to the difficult accessibility of these values. Three types of cars were modeled - SEDAN, SUV and MPV with the characteristics of the vehicle fronts (Table 3) that represent the types of such cars in these classes (Figure 3). 
Table 2: Parameters of cars.

\begin{tabular}{|l|c|c|c|}
\hline & SEDAN & SUV & MPV \\
\hline Height of impact edge (m) & 0,42 & 0,66 & 0,50 \\
\hline Height of leading edge of hood (m) & 0,63 & 0,90 & 0,70 \\
\hline Height of the end of hood (m) & 0,83 & 1,12 & 1,00 \\
\hline Length of hood (m) & 0,70 & 0,77 & 0,60 \\
\hline Angle of hood (degrees) & 16,6 & 16,6 & 30,0 \\
\hline Length of windshield (m) & 0,96 & 0,96 & 1,10 \\
\hline Height of upper edge of windshield $(\mathrm{m})$ & 1,36 & 1,65 & 1,60 \\
\hline
\end{tabular}
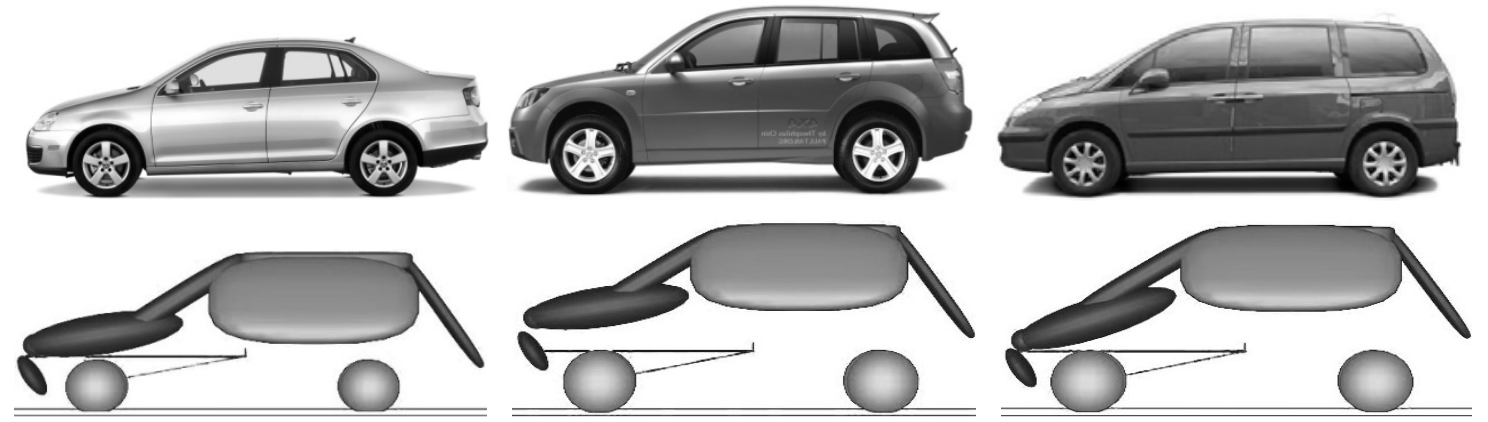

Figure 3: Types of cars (SEDAN, SUV, MPV).

The roadway is represented by a horizontal surface with high stiffness. The characteristics of the roadway and the contact as a factor of friction and the attenuation coefficient are also adopted.

There were 48 simulations made of the most common type of collision - the side-impact (Broadside). According to ISO 13232 for motorcycles it is a configuration of objects 143 . The cyclist was moving at $15 \mathrm{~km} / \mathrm{h}$ upright to the direction of driving car. The car crashed into the left side of the cyclist. The initial vehicle speed was $35 \mathrm{~km} / \mathrm{h}, 40 \mathrm{~km} / \mathrm{h}$ and $65 \mathrm{~km} / \mathrm{h}$., and the deceleration was $8.0 \mathrm{~m} . \mathrm{s}^{-2}$ in all cases. It corresponds to intense or panic braking. The primary and the secondary contact with the car body were studied in particular and then the trajectory of the cyclist's movements both in the air and on the land, including tertiary contact.

\section{FLIGHT OF A CYCLIST AND THE FALL ONTO THE GROUND}

The movement of cyclists in the air (flight) is mostly influenced by the car's speed at the moment of impact. According to the trajectory of a cyclist, the speed can be described as low or high. With low speed the cyclist does not fly over the roof of the car, whereas with high speed the cyclist flies over the roof of the car. In our simulations at 35 and $40 \mathrm{~km} / \mathrm{h}$ there was no flight over the roof. At a speed of $65 \mathrm{~km} / \mathrm{h}$ flight occurred with the SEDAN and MPV.

The cyclist was thrown diagonally forward with rotation in the driving direction of the car by the SEDAN. The SUV-type of car with a broad vehicle front and high impact edge ladled the cyclist with the front and swiped them slightly sidelong forward. The body found itself all the time in a lower position than with the SEDAN. The cyclist was swiped sidelong forward 
by MPV, as well as by the SEDAN. However, the movement resultant was steeper and the flight height was higher, because of shorter and more sloping vehicle front.

The trajectory of movement at the speed of $65 \mathrm{~km} / \mathrm{h}$ is characterized by the flight over the roof by the SEDAN (Figure 4) and by the MPV (Figure 6). A stronger swipe forward in front of the vehicle was observed by the SUV (Figure 5).

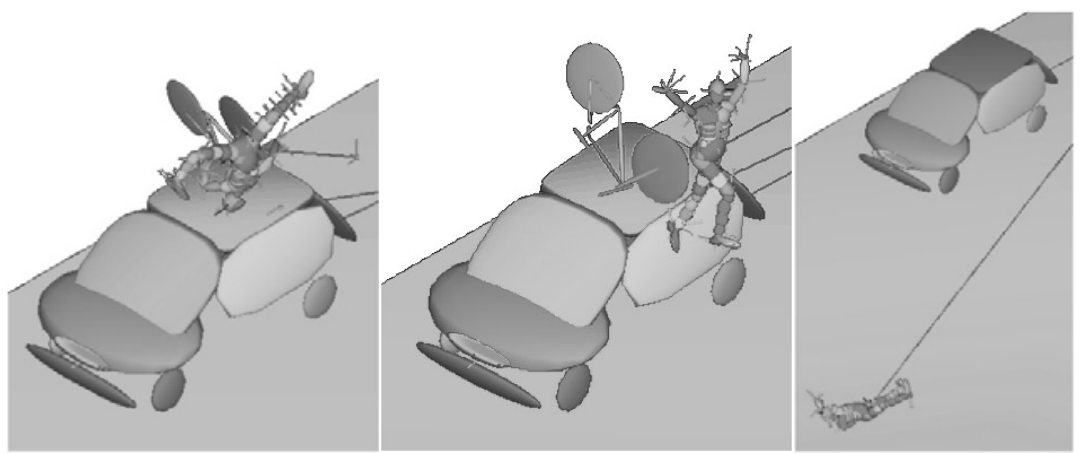

Figure 4 - Strike of the cyclist - SEDAN - $65 \mathrm{~km} / \mathrm{h}$.

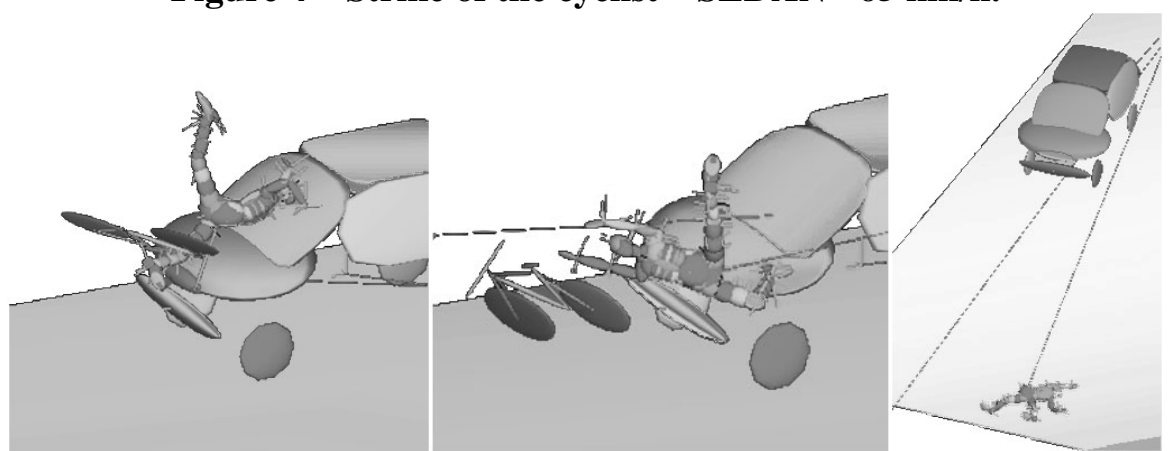

Figure 5 - Strike of the cyclist - SUV - $65 \mathrm{~km} / \mathrm{h}$.

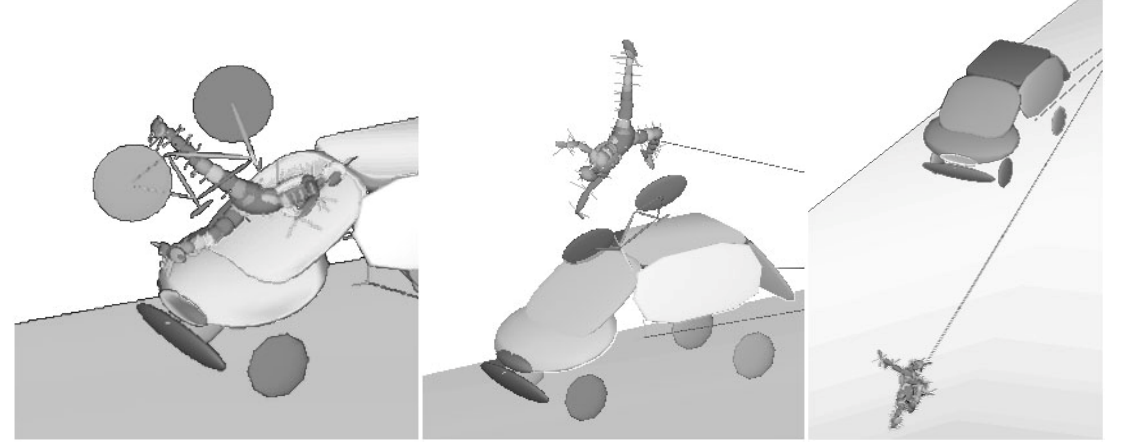

Figure 6 - Strike of the cyclist - MPV - $65 \mathrm{~km} / \mathrm{h}$.

\section{SUMMARY}

Comparing the results from our Madymo simulation and the real Crash Tests carried out by Broker et al. (2006), we can conclude that the simulations show consistent patterns in: the shape of the front of the car (height of impact edge), the speed just before the impact, height of cyclist center of mass and the throw direction. Either flight over the hood or only the ladling of the cyclist and their swipe forward can be observed in a dependence on the speed. If the impact edge of the car is below the cyclist's center of mass the body is rotated and swiped up sidelong forward. If the impact is in the center of mass the cyclist is ladled up by the car and then swiped forward in front of the car.

Both the movement of the bike and the spot of the fall on the ground were consistent with the results of the crash tests carried out by (Broker, et al., 2006). The throw distance 
of the bike was larger than the throw distance of the cyclist, the linear regression is $y=2.94 x$ 25.5 (for the bike) and $y=2.36 x-14.8$ (for the cyclist) out of 105 crash tests. The throw distance of the bike was always longer than the throw distance of the cyclist in our simulations.
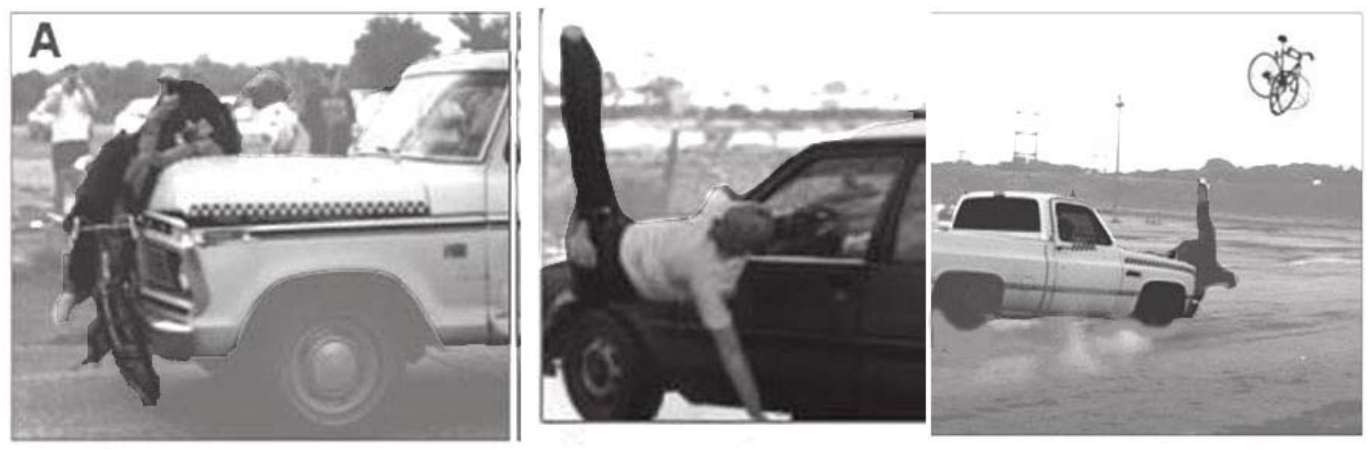

Figure 7 - Demonstration of the crash tests carried by Broker, et al (2006).

To analyze the cyclist accident using the relations relevant for pedestrian throw, the car speed just before the impact was $40 \mathrm{~km} / \mathrm{h}$. The throw distance for each type of car and the position of the cyclist are in Table 4. The speed determined by using the Schmidt et al. (1971) relation differs on average by $3.3 \mathrm{~km} / \mathrm{h}$ and approaches the best of all noninterval methods the speed of $40 \mathrm{~km} / \mathrm{h}$, while the smallest deviations are observed by the SUV and the MPV. The speed according to Collins, et al. (2000) differs on average by $6.3 \mathrm{~km} / \mathrm{h}$, according to Limpert (1999) by $8 \mathrm{~km} / \mathrm{h}$ and according to Fugger, et al. (2000) by $10.5 \mathrm{~km} / \mathrm{h}$. If the interval method (Wood, 1997) was used then the calculated speed was correspondent with the SUV and the MPV. The values calculated according to Searle, et al. (1983) were slightly below the real speed, mainly with the SUV and the MPV.

The used relations were initially meant to analyze the pedestrian impact. We must take into account that the initial speed of a cyclist is higher - in our case $15 \mathrm{~km} / \mathrm{h}$., with pedestrians the maximum is $5 \mathrm{~km} / \mathrm{h}$. The total speed of the impact is higher with cyclist and consequently also the flight is longer. Another difference is the height of center of mass of the cyclist compared to that of the pedestrian. The cyclist's center of mass is higher and also the height of flight of the cyclist is higher, and consequently also the throw distance is longer.

Table 3 - Calculation of the car's speed just before the collision.

\begin{tabular}{|c|c|c|c|c|c|c|c|c|c|c|c|c|c|c|}
\hline $\begin{array}{c}\text { Type of } \\
\text { car }\end{array}$ & $\begin{array}{c}\text { Type of } \\
\text { bike } \\
\text { (position } \\
\text { of cyclist) }\end{array}$ & $\begin{array}{c}\text { Throw } \\
\text { distance } \\
\text { (m) }\end{array}$ & & $\begin{array}{l}\text { nidt, } \\
\text { al. } \\
\text { 71) } \\
\text { act } \\
\text { ed / } \\
\text { tion) } \\
\end{array}$ & $\begin{array}{r}\text { Col } \\
\text { al. } \\
\text { (in } \\
\text { sp } \\
\text { dev }\end{array}$ & $\begin{array}{l}\text { ins, et } \\
\text { 1979) } \\
\text { pact } \\
\text { ed / } \\
\text { ation) }\end{array}$ & & $\begin{array}{l}\text { ert } \\
\text { 9) } \\
\text { act } \\
\text { d / } \\
\text { tion) }\end{array}$ & $\begin{array}{r}\text { (ir } \\
\text { SF } \\
\text { dev }\end{array}$ & $\begin{array}{l}\text { ger, et } \\
\text { 2000) } \\
\text { pact } \\
\text { eed / } \\
\text { ation) }\end{array}$ & $\begin{array}{r}\mathrm{m} \\
\mathrm{m} \\
(\mathbf{k n}\end{array}$ & & & \\
\hline \multirow{3}{*}{ SEDAN } & Mountain & 6,91 & 34 & $15 \%$ & 30 & $25 \%$ & 29 & $28 \%$ & 27 & $33 \%$ & 28 & 34 & 25 & 36 \\
\hline & Road & 6,45 & 33 & $18 \%$ & 29 & $28 \%$ & 27 & $32 \%$ & 26 & $35 \%$ & 27 & 33 & 24 & 35 \\
\hline & Touring & 7,25 & 35 & $13 \%$ & 31 & $22 \%$ & 30 & $26 \%$ & 28 & $31 \%$ & 29 & 35 & 26 & 37 \\
\hline \multirow{3}{*}{ SUV } & Moun & 9,79 & 40 & $0 \%$ & 39 & & 37 & $8 \%$ & 33 & $17 \%$ & 34 & 41 & 27 & 43 \\
\hline & Road & 8,41 & 38 & $6 \%$ & 35 & $13 \%$ & 33 & $17 \%$ & 30 & $24 \%$ & 31 & 38 & 25 & 40 \\
\hline & Touring & 8,45 & 38 & $6 \%$ & 35 & $13 \%$ & 33 & $17 \%$ & 30 & $24 \%$ & 31 & 38 & 25 & 40 \\
\hline \multirow{3}{*}{ MPV } & Mountain & 8,84 & 38 & $4 \%$ & 36 & $10 \%$ & 34 & $14 \%$ & 31 & $22 \%$ & 32 & 39 & 29 & 41 \\
\hline & Road & 7,92 & 36 & $9 \%$ & 33 & $17 \%$ & 32 & $21 \%$ & 29 & $27 \%$ & 30 & 36 & 27 & 40 \\
\hline & Touring & 8,51 & 38 & $6 \%$ & 35 & $12 \%$ & 33 & $17 \%$ & 31 & $24 \%$ & 32 & 38 & 28 & 40 \\
\hline
\end{tabular}




\section{CONCLUSION}

If we compare the issue of the impact with a cyclist and the impact with a pedestrian we can conclude the mechanisms are alike. The speed before impact is supposed to be higher with the cyclist which is why the impact seems to be more serious. The higher speed with the side impact can cause the cyclist to fall on to the front hood sidelong. A positive consequence of the speed of cyclist with the side impact is that the cyclist slides on the front splashboard. Another difference is in the position of center of mass - that of the cyclist's is higher, and in the mutual position of center of mass of cyclist and the impact edge of a car.

Regarding the possibility of using the relations designed to estimate the impact speed based on pedestrian throw distance, we can use the formulas for cyclist side impact accidents only to a limited extent. The most suitable is the Schmidt et al. (1971) formula and the interval method of calculation by Wood (1997) but only for SUVs and MPVs.

\section{ACKNOWLEDGEMENTS}

This project is supported by GAČR P 407/10/1624 and GAUK 111310.

\section{REFERENCES}

Broker, Jeffrey and Hill, Paul. 2006. Bicycle Accidents: biomechanical, engineering, and legal aspects. Tucson : Lawyers \& Judges Publishing Company, Inc., 2006. ISBN 0913875-90-2.

Collins, J. C. and Morris, J. L. 1979. Accident Reconstruction. Highway Collision Analysis. 1979, pp. 240-242.

Fugger, T., Randles, B. and Eubanks, J. J. 2000. Comparsion of Pedestrian and accident reconstruction model to experimental test data for wrap trajectories. ImechE Conference Transactions: Vehicle Safety. 2000, pp. 104-122.

Limpert, R. 1999. Motor Vehicle Accident Reconstruction and Analysis. Charlotte : Michie Butterwoeth, 1999. Vol. Second Edition.

Searle, J.A. and Searle, A. 1983. The trajectories of pedestrians, motorcycles, motorcyclists, etc. following a road accident. Proceedings of the 27th Stapp Car Crash Conference. 1983.

Schmidt, D. N. and Nagel, D. A. 1971. Pedestrian Impact Case Study. Proceedings of $15^{\text {th }}$ Conference Association for Automotive Medicine. 1971.

Wood, D. P. 1997. Determination of speed from pedestrian throw In Forensic Accident Investigation: Motor Vehicles. Charlotte : Michie Butterworth, 1997.

Bike Accident Summary, 2010. Traffic Operations. [Online] 01 19, Bike Accident Summary, 2010. [Cited: 02 25, 2010.] http://www.fcgov.com/traffic/pdf/bike_accident_summary.pdf.

iBESIP. 2008. Používejte cyklistické přilby. iBESIP. [Online] 2008. [Cited: 1 9, 2010.] www.ibesip.cz/files/=220/Pouzivejte_cyk1_prilby.doc. 